\title{
GAS ADSORPTION EQUILIBRIA
}

\author{
Experimental Methods and \\ Adsorptive Isotherms
}




\title{
GAS ADSORPTION EQUILIBRIA
}

\section{Experimental Methods and Adsorptive Isotherms}

\author{
Jürgen U. Keller \\ Reiner Staudt \\ Universität Siegen \\ Germany
}

Springer 
eBook ISBN: $\quad 0-387-23598-1$

Print ISBN: $\quad 0-387-23597-3$

C2005 Springer Science + Business Media, Inc.

Print C2005 Springer Science + Business Media, Inc.

Boston

All rights reserved

No part of this eBook may be reproduced or transmitted in any form or by any means, electronic, mechanical, recording, or otherwise, without written consent from the Publisher

Created in the United States of America

Visit Springer's eBookstore at:

http://ebooks.kluweronline.com

and the Springer Global Website Online at:

http://www.springeronline.com 


\section{CONTENTS}

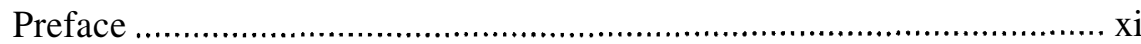

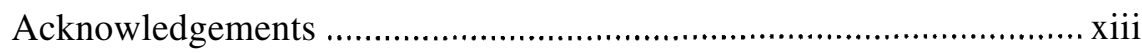

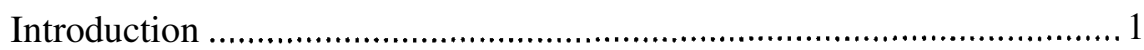

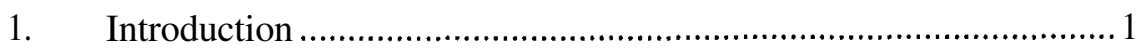

2. Gas Adsorption Processes in Separation Technology ....................2

3. Experimental Methods ..............................................................6

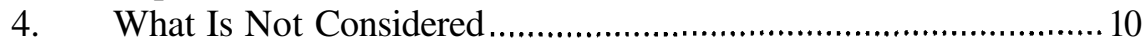

References ......................................................................... 11

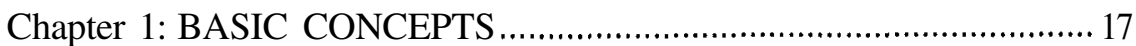

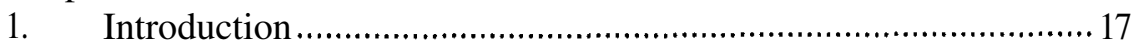

2. Adsorption Phenomena .......................................................... 18

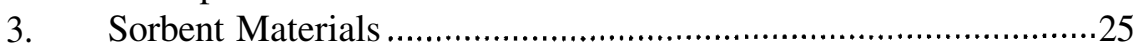

4. Characterization of Porous Solids.................................................31

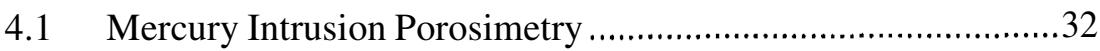

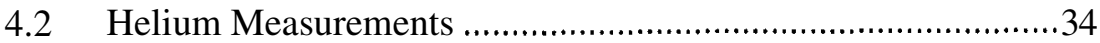

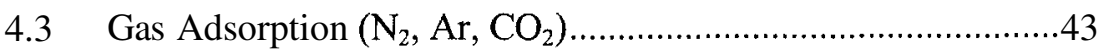

5. Mass and Volume of Adsorbed Phases.......................................52

5.1 Models for the Void Volume $\left(\mathrm{V}^{\mathrm{s}}\right)$ of a Sorbent Material and the Volume $\left(\mathrm{V}^{\mathrm{a}}\right)$ of a Sorbate ...........................................56

5.2 Outline of Calorimetric-Dielectric Measurements of Absolute Masses of Adsorbates ..............................................66

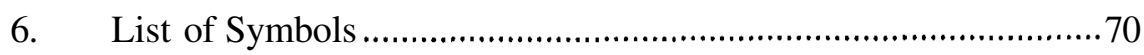

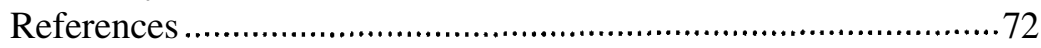

Chapter 2: VOLUMETRY / MANOMETRY …......................................79

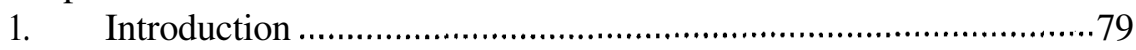

2. Volumetric Measurement of Pure Gas Adsorption

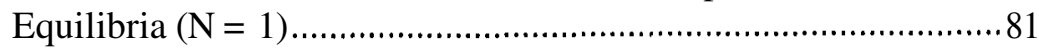

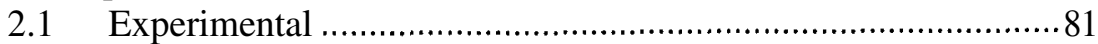

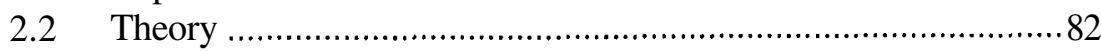

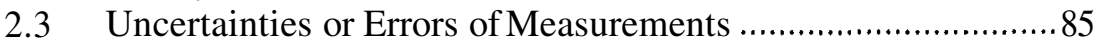

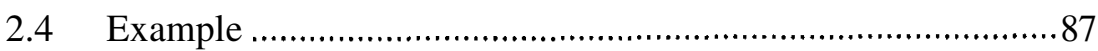

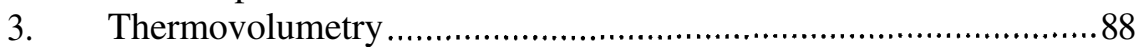

4. Volumetric Measurement of Multicomponent Gas

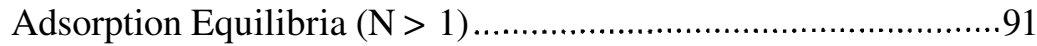




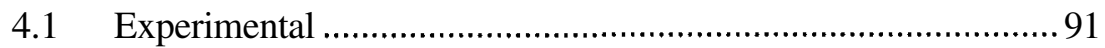

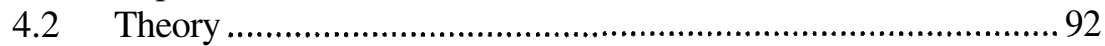

4.3 Uncertainties or Errors of Measurements ................................ 94

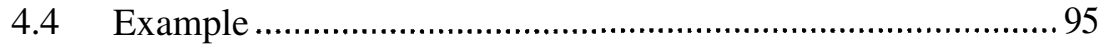

5. Volumetric - Calorimetric Measurements

The Sensor Gas Calorimeter (SGC) ............................................ 97

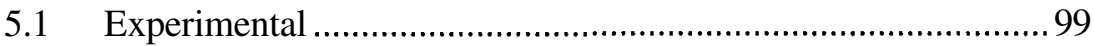

5.2 Outline of Theory and Calibration........................................ 103

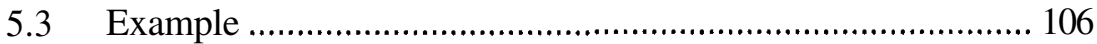

6. Pros and Cons of Volumetry / Manometry............................... 109

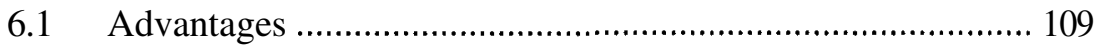

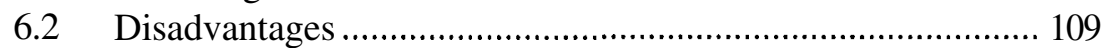

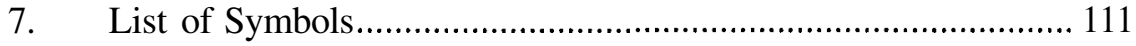

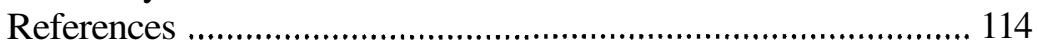

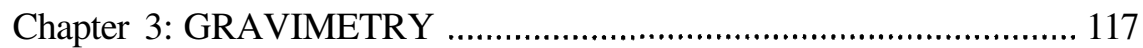

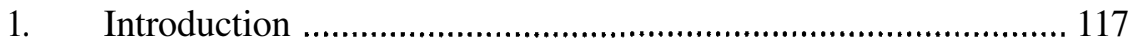

2. Gravimetric Measurements of Pure Gas Adsorption

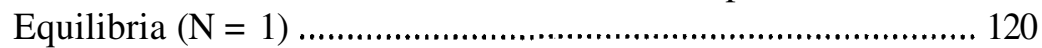

2.1 Two Beam Balances ............................................................. 120

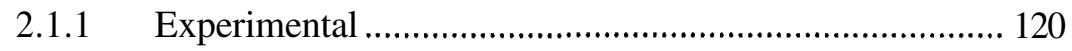

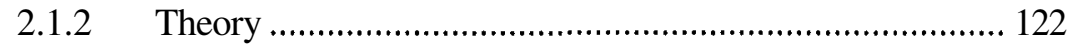

2.1.3 Uncertainties or Errors of Measurements ...................... 127

2.2 Single Beam Balances ..................................................... 129

2.2.1 Experimental ........................................................ 129

2.2.2 Theory .................................................................... 131

2.2.3 Uncertainties or Errors of Measurements ..................... 134

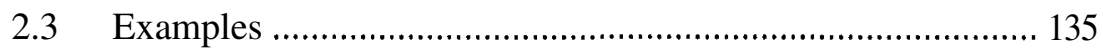

3. Thermogravimetry .................................................................. 153

4. Gravimetric Measurement of Multicomponent Gas

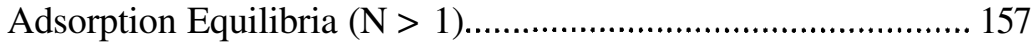

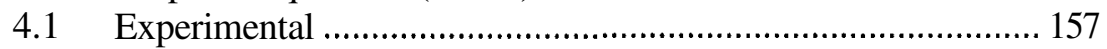

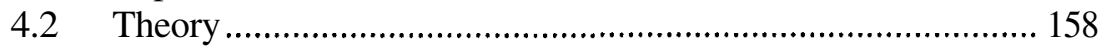

4.3 Uncertainties or Errors of Measurement.............................. 161

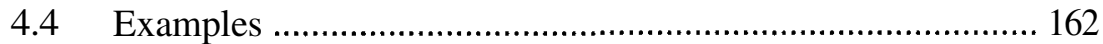

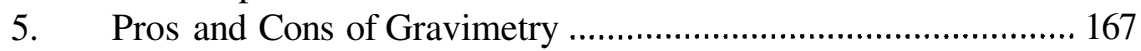

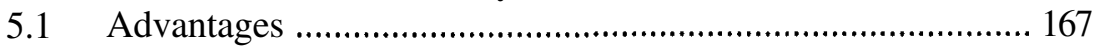

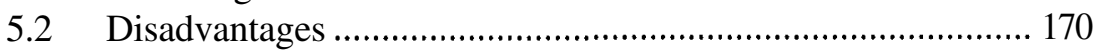

6. List of Symbols and Abbreviations ......................................... 171

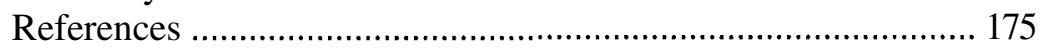


Chapter 4: VOLUMETRIC - GRAVIMETRIC MEASUREMENTS .. 181

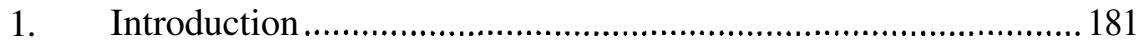

2. Volumetric - Gravimetric Measurements of Binary

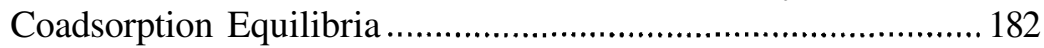

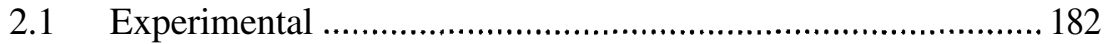

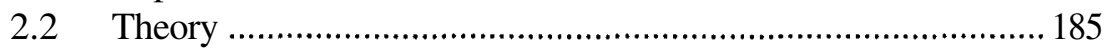

2.3 Uncertainties or Errors of Measurement .................................. 191

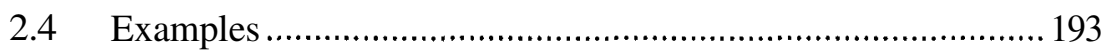

3. Densimetric - Gravimetric Measurements of Binary

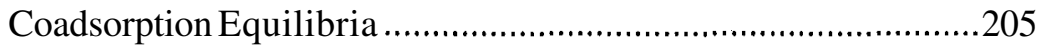

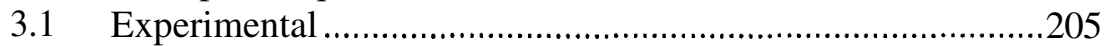

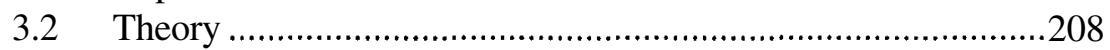

3.3 Uncertainties or Errors of Measurement ...............................213

3.4 Example ...............................................................................214

3.5 Densimetric-Volumetric Measurements of Binary Coadsorption Equilibria .......................................................218

3.6 Volumetric-Densimetric Measurements of Wall Adsorption .222

4. Pros and Cons of Volumetric-Gravimetric Measurements of Binary Coadsorption Equilibria .............................................225

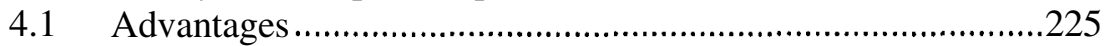

4.2 Disadvantages ..................................................................226

4.3 Comparison of Densimetric-Gravimetric and Densimetric-Volumetric Binary Coadsorption Measurements ........227

5. List of Symbols and Abbreviations.........................................229

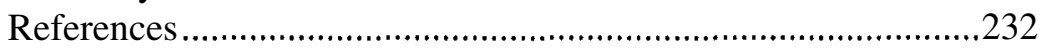

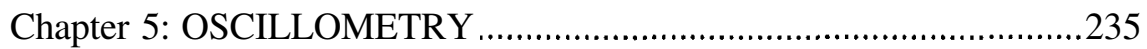

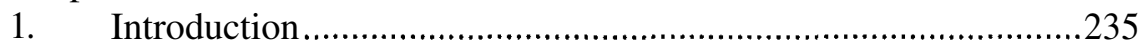

2. Measurement of Pure Gas Adsorption Equilibria $(\mathrm{N}=1)$

by Slow Oscillations of a Rotational Pendulum .........................2237

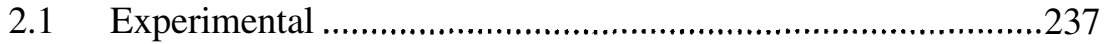

2.2 Outline of Theory ................................................................240

2.2.1 The Motion of the Pendulum in Vacuum........................241

2.2.2 The Motion of the Pendulum in Sorptive Gas.................243

2.3 Uncertainties or Errors of Measurement ................................251

$2.4 \quad$ Examples ...............................................................................252

3. Oszillometric - Gravimetric Measurements of

Gas Absorption in Swelling Materials .....................................256

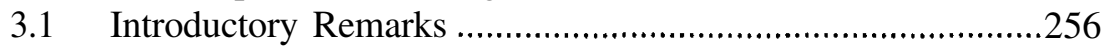

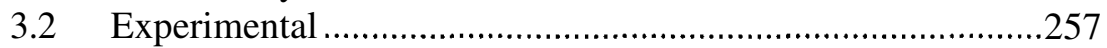

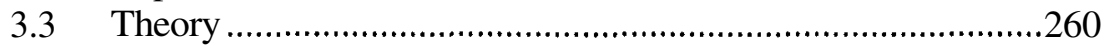

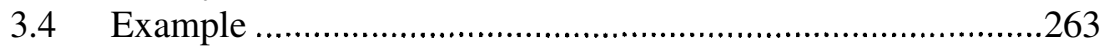


4. Oscillometric - Manometric Measurements of Gas Absorption in Swelling Materials............................................2265

4.1 Introductory Remarks ......................................................... 265

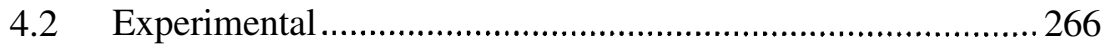

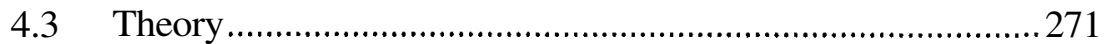

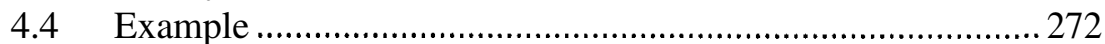

5. Pros and Cons of Oscillometry .................................................... 275

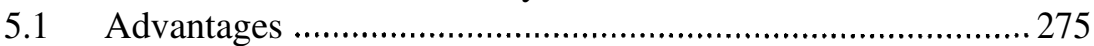

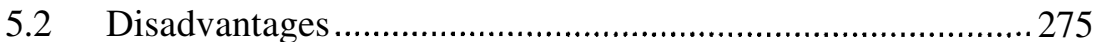

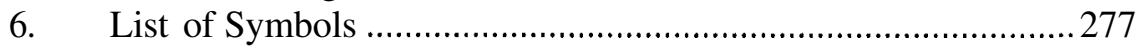

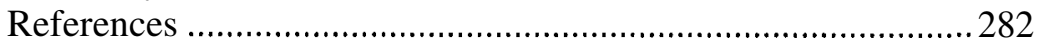

Chapter 6: IMPEDANCE SPECTROSCOPY ….................................. 287

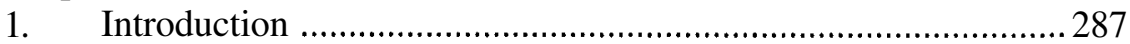

2. Dielectric Measurements of Gas Adsorption Systems ..............289

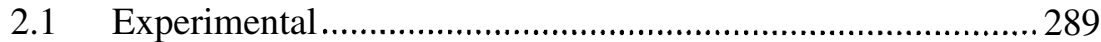

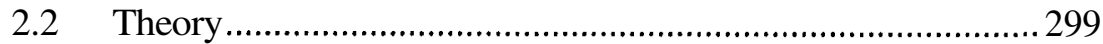

2.2.1 Basic Concepts..............................................................2299

2.2.2 Polarization of Dielectrics............................................. 302

2.2.3 Models for the Complex Permittivity of Dielectric Sorbent-Sorbate Systems .................................................. 306

2.3 Uncertainties of Dielectric Measurements of

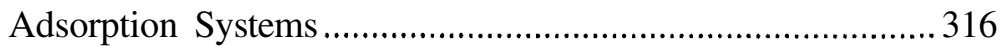

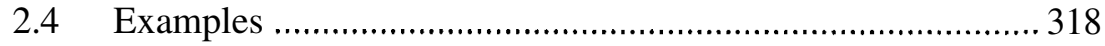

3. Dielectric-Manometric and Dielectric-Gravimetric

Measurements of Pure Gas Adsorption Equilibria ..................... 332

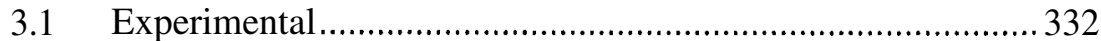

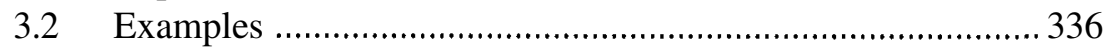

3.3 Impedance Measurements in Adsorption Reactors ................ 342

4. Pros and Cons of Impedance Spectroscopy ................................349

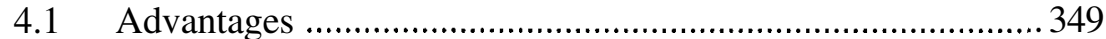

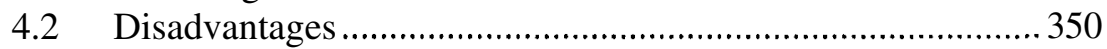

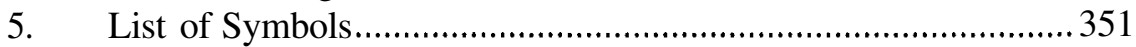

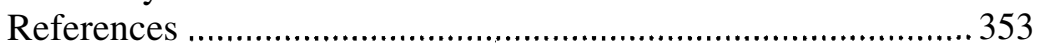

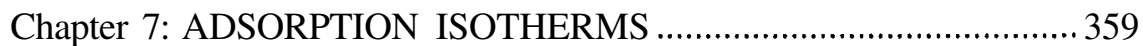

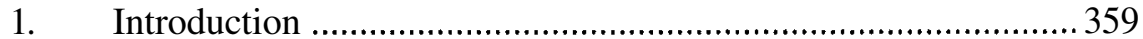

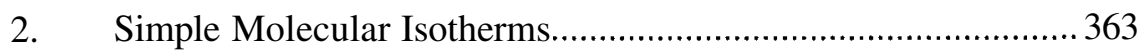

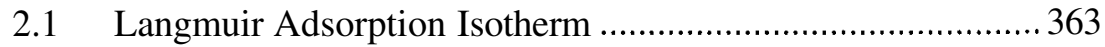

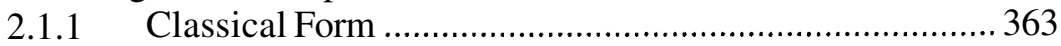

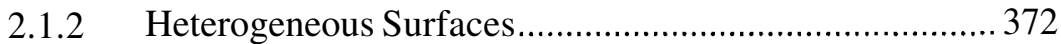

2.1.3 Admolecules with Interactions ..................................... 377 


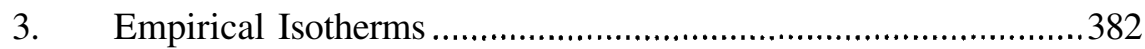

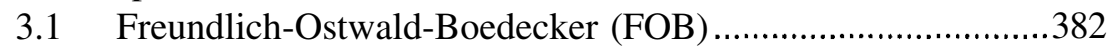

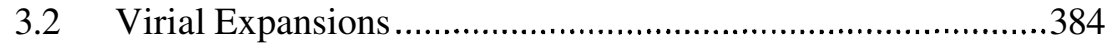

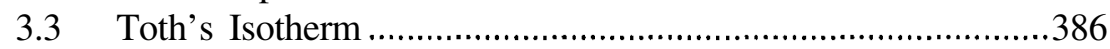

3.4 Brunauer-Emmett-Teller Isotherm (BET) _............................387

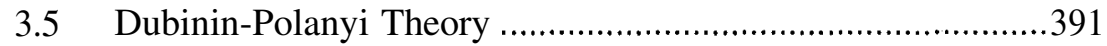

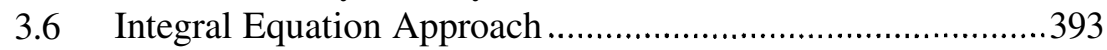

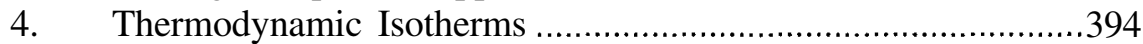

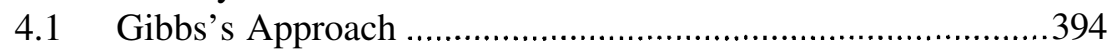

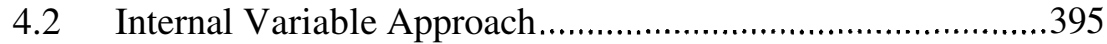

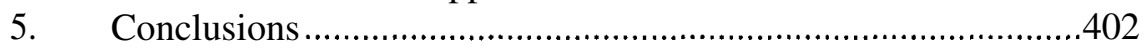

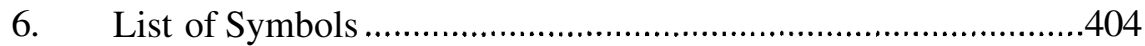

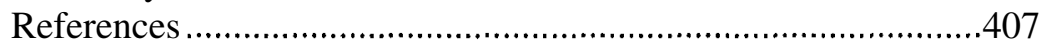

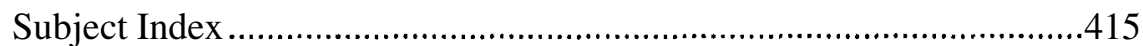

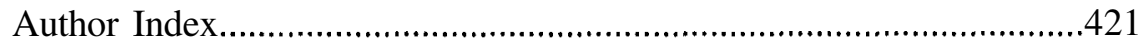




\section{PREFACE}

This book is intended to present for the first time experimental methods to measure equilibria states of pure and mixed gases being adsorbed on the surface of solid materials. It has been written for engineers and scientists from industry and academia who are interested in adsorption based gas separation processes and/or in using gas adsorption for characterization of the porosity of solid materials.

This book is the result of a fruitful collaboration of a theoretician (JUK) and an experimentalist (RS) over more than twelve years in the field of gas adsorption systems at the Institute of Fluid- and Thermodynamics (IFT) at the University of Siegen, Siegen, Germany. This collaboration resulted in the development of several new methods to measure not only pure gas adsorption, but gas mixture or coadsorption equilibria on inert porous solids. Also several new theoretical results could be achieved leading to new types of so-called adsorption isotherms based on the concepts of molecular association and phenomenologically speaking - on that of thermodynamic phases of fractal dimension. Naturally, results of international collaboration of the authors over the years (1980-2000) also are included.

Both, traditional and new measurement methods for gas adsorption equilibria are presented in Chaps. 2-6 and elucidated by quite a number of experimental data sets, most of them having been measured in our laboratories. Special emphasis is given to uncertainties of data and pros and cons of all measurement methods are given to the best of our knowledge. Also the basic concepts underlying interpretation of measurements and calculations of adsorbed masses from measurement signals, are discussed in Chap. 1. 
In publishing this book the authors hope to contribute to

- the development of effective and reliable methods to measure pure gas and gas mixture adsorption equilibria;

- preventing young (and old) experimenters from doing all the mistakes we have done during our laboratory work*;

- making experimental gas adsorption data measured today in many laboratories all over the world more easily comparable to each other, as methods and procedures should be come more and more similar and possibly also will be standardized (IUPAC) in the years to come.

In view of the complexity of interaction of molecules from fluid, i. e. gaseous or liquid phases with the atoms of the surface of a solid material the authors have put their emphasis on experimental measurement methods approaching especially mixture adsorption phenomena. Of course we are well aware that simulation of adsorption systems based on molecular models is making considerable progress. This especially is promoted by still growing computer capacities and new and powerful software and simulation programs. However, reality is in experiment, not in computer's silica. There only our present knowledge and model of physical-chemical reality can be reflected. Nevertheless, we expect in future a combination of highly selective chosen key experiments and computer simulations to be the most effective way to make progress in the complex field of gas mixture adsorption equilibria and probably also in some neighboring fields like adsorption kinetics. However, all these interesting fields of adsorption science including applications of adsorption phenomena to chemical engineering are not considered here but left to other authors.

In view of space limitations neither all of the experimental details and tricks of the various measurement methods nor all of the analytic arguments of the underlying theories could be presented. If readers do have questions they are cordially invited to approach the authors, namely for the former RS $\left.{ }^{* *}\right)$ for the later $\mathrm{JUK}^{* *}$.

*) A true experimenter pursues his goal till everything in the lab is ruined. Often only then he becomes aware that nobody has taken notes of what was done and what has really happened (W. Sibbertsen, 1990).

**) keller@ift.maschinenbau.uni-siegen.de

Staudt@inc.uni-leipzig.de 
As we are well aware of the fact that not many readers do have time to read a book like this cover to cover, we always have tried to present the material in nearly self-contained separate chapters. For this reason we also have provided the literature separately for each chapter being aware of the fact that some books and papers on gas adsorption may have been cited more than once.

\section{Acknowledgements}

It is now our pleasure to express our grateful thanks to all of our undergraduate and graduate students who have been engaged in project work at IFT in the field of gas adsorption during the years (1984-2004). Among them especially the contributions of F. Dreisbach, N. Iossifova, H. Rave, M. Seelbach and M. Tomalla are highly appreciated.

Thanks for cooperation and discussions at international conferences (FOA, COPS, PBCAST) and at private meetings are due to our colleagues
W. Arlt
J. Kärger
D. M. Ruthven
G. V. Baron
K. Kaneko
A. Sakoda
W. Bongartz
H. von Kienle
M. Sakuth
St. Brandani
K. S. Knaebel
Sh. Sircar
J. Cyprian
K.-F. Krebs
F. Stoeckli
D. D. Do
E. Krumm
D. Sunderer
J. Fritzsche
M. D. Le Van
M. Suzuki
L. Fuller
H.-W. Lösch
O. Talu
U. von Gemmingen
F. Metz
M. Thommes
A. Guillot
P. Monson
K. Unger
Ch. Haynes
A. L. Myers
R. T. Yang
R. $\mathrm{He}$
A. W. Neimark
H. Yoshida
K.-D. Henning
B. Roehl-Kuhn
Li Zhou
U. Hoffmann
J. Rouquerol
W. Zimmermann
M. Jaroniec
W. Rudzinski

Special thanks are given to W. A. Steele, College Park, for reading the manuscript of the book and helping to improve the English wording. Thanks are also due to J. M. Prausnitz, Berkeley and J. A. Clark, Ann Arbor, USA, for reading chapter 3, Gravimetry, of the manuscript and contributing valuable hints and remarks to its contents.

Special tribute is also paid to K. S. W. Sing, Exeter, UK for several stimulating lectures given at IFT during (1992-1998) and also for discussions on fundamental aspects of gas adsorption systems. 
Cordial thanks are also given to our colleague and friend Prof. h. c. Erich Robens, Friedrichsdorf and Mainz, for fruitful and interesting discussions over many years on the porosity of solids and also for valuable hints to experimental measurement procedures.

Several people have contributed to realize this monography by processing the manuscript: Mrs U. Schilk did the excellent typing and formatting of the text with never ending patience and Mr M. U. Göbel did the art work, contributing also many ideas to Figures and Diagrams. Both of them are given our sincere thanks for devotion and dedication to this work.

Last not least we would like to express our gratitude to the Publishers, especially to Mrs C. Day and Mrs D. Doherty for providing useful information in layout and styling of the manuscript and for several encouraging e-mails and notes.

Siegen - Weidenau

J. U. Keller
Leipzig

R. Staudt 